\title{
BIOEQUIVALENCE OF TWO BRANDS OF CITALOPRAM 40 mg TABLETS AFTER SINGLE ORAL ADMINISTRATION TO HEALTHY VOLUNTEERS
}

\author{
Luis Mendoza ${ }^{\mathrm{a} *}$, Marián Hajdúch ${ }^{\mathrm{b} \#}$, Hana Kekulováa, Xenia Svobodováa, Vladimír Mihál ${ }^{\mathrm{b}}$, \\ Michal Svoboda ${ }^{a}$
}

a I.Q.A., a.S., Jindřicha Plachty 16, 150 00, Prague 10, Czech Republic

${ }^{b}$ Laboratory of Experimental Medicine, Department of Pediatrics, Faculty of Medicine, Palacky University and University in Olomouc, Olomouc, Czech Republic

\# both autors equally contributed to the work

e-mail:mendoza@iqa.cz

Received: April 27, 2005; Accepted: June 7, 2005

Key words: Citalopram/AUC/Bioequivalence/Pharmacokinetics/HLPC

A randomized, two-way, crossover, bioequivalence study was conducted in 26 fasting, healthy, male volunteers to compare two brands of citalopram $40 \mathrm{mg}$ tablets, Citol (Abdi Ibrahim İlaç San. ve Tic A.Ş., Istanbul, Turkey) as a test and Cipramil ${ }^{\circledR}$ (H. Lundbeck A/S, Copenhagen, Denmark) as a reference product. One tablet of either formulation was administered with low-carbonate water after $10 \mathrm{~h}$ of overnight fasting. After dosing, serial blood samples were collected during a period of 24 hours. Plasma samples were analysed for citalopram by a validated HPLC method. The pharmacokinetic parameters AUC0-24, $\mathrm{AUC}_{0-\alpha}, \mathrm{C}_{\max }, \mathrm{T}_{\max }, \mathrm{K}_{\mathrm{el}}, \mathrm{T}_{1 / 2}$, and CL were determined from plasma concentration-time profiles for both formulations and were compared statistically to evaluate bioequivalence between the two brands of citalopram, using the statistical modules recommended by FDA. The analysis of variance (ANOVA) did not show any significant difference between the two formulations and $90 \%$ confidence intervals (CI) fell within the acceptable range for bioequivalence. Based on these statistical inferences it was concluded that the two brands

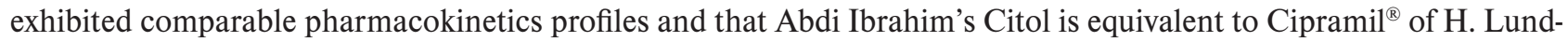
beck, Copenhagen, Denmark.

\section{INTRODUCTION}

Citalopram, 1-[3-(dimethylamino)propyl]-1-(4-fluorophenyl)-1,3-dihydroisobenzofuran-5-carbonitrile, is a drug which belongs to the group of specific serotonin reuptake inhibitors ${ }^{1}$. It is used alone or in combination with other antidepressive and antipsychotic drugs to help treat a variety of psychiatric disorders ${ }^{2}$. Citalopram has shown efficacy in placebo-controlled clinical studies ${ }^{3,4}$ and has been marketed in several countries for the treatment of major depression. Citalopram is a fine, white powder that is sparingly soluble in water and soluble in ethanol. It is available as film-coated, round or oval, white, scored tablets containing citalopram hydrobromide, corresponding to 10, 20, 30 or $40 \mathrm{mg}$ of citalopram base and as infusion concentrate and drops containing citalopram hydrochloride.

The objective of this study was to evaluate, in healthy volunteers, the bioequivalence of a test formulation of the $40 \mathrm{mg}$ (tablets) of citalopram elaborated by Abdi Ibrahim İlaç San. ve Tic A.Ş., Istanbul, Turkey (Citol) and a commercial formulation of $40 \mathrm{mg}$ (tablets) of citalopram (Cipramil ${ }^{\circledR}$ made by H. Lundbeck, Copenhagen, Denmark used as a reference formulation.

\section{MATERIALS AND METHODS}

\section{Volunteers characteristics}

Twenty-six healthy adult male volunteers aged between 18 and 50 years $(29.0 \pm 2.1$ years, mean \pm S.D.; range 27-32) and within the $15 \%$ of the ideal body weight, weight between 55.0 and $77.0 \mathrm{~kg}(65 \pm 9.0)$, and height between 166 and $183 \mathrm{~cm}(177 \pm 7.0)$, were selected for the study. The estimation of the number of subjects required was determined taking into account the error variance associated with the primary pharmacokinetic parameters as estimated from published data, the probability of the confidence interval for relative bioavailability (95\%), and the required power $(80 \%)^{5}$.

All subjects gave written informed consent and the Local Ethics Committee (University Hospital in Olomouc) has approved the clinical protocol. All volunteers were assessed as healthy based on medical history, clinical examination, blood pressure, ECG and laboratory investigation (hematology, blood biochemistry and urine). There were no individuals with either a history or evidence of hepatic, renal, gastrointestinal, and hematological deviations, or any acute/chronic disease or drug allergy. 
The study was conducted in a randomized, single-dose, two-way, cross-over design with a 2-week washout period between two doses. During each period, the volunteers were admitted to hospital and after an overnight fasting they received a single reference or tested $40 \mathrm{mg}$ citalopram tablet. Low-carbonate water $(240 \mathrm{~mL})$ was given immediately after drug administration. All volunteers fasted $2 \mathrm{~h}$ after the drug administration, thereafter they received unified snack. The standardized meals (lunch, afternoon snack, dinner and breakfast) were provided to volunteers 6, 9, 12 and $24 \mathrm{~h}$ after dosing. No other food was permitted during the first $24 \mathrm{~h}$ after drug administration. Liquid consumption was permitted ad libitum after lunch, however xanthine-containing drinks like tea, coffee and cola were avoided.

The study was performed in accordance with the guidelines of the revised Declaration of Helsinki on biomedical research involving subjects and the requirements of Good Clinical Practice.

\section{Formulations and Sample Collection}

The following formulations were employed: Citol $40 \mathrm{mg}$ tablets (lot number 207002-D, expiration date 07/ 2004) as test formulation, and Cipramil ${ }^{\circledR} 40 \mathrm{mg}$ tablets (lot number 763A, expiration date 07/2006) as reference formulation.

Blood (9 ml) was sampled from antecubital or cubital veins and collected into EDTA-containing tubes before and $1,1.5,2,3,4,6,8,10,12,16$ and 24 hours after the administration of each citalopram tablet formulation (40 mg). The blood samples were centrifuged at $1500 \mathrm{~g}$ for $10 \mathrm{~min}$ at $4^{\circ} \mathrm{C}$ and the separated plasma was collected and stored at $-20{ }^{\circ} \mathrm{C}$ until drug analysis. After a wash-out period of 14 days, the study was repeated in the same manner to complete the cross-over design.

\section{Sample Preparation for HLPC Injection}

Ten $\mu 1$ of the internal standard working solution (verapamil $100 \mu \mathrm{l} / \mathrm{ml}$ ) was added to $1 \mathrm{ml}$ plasma sample. The samples were vortexed for $2 \mathrm{~min}$ and $2 \mathrm{ml}$ of a mixture of potassium dihydrogenphosphate and methanol $(85: 15, v / v)$ were added. This mixture was then shaken on a vortex mixer for $2 \mathrm{~min}$ and centrifuged at $2500 \mathrm{~g}$ for $5 \mathrm{~min}$ in order to spin down protein aggregates. The final supernatant was applied directly to a solid phase extraction column. Aliquots were loaded into an autosampler tray and volumes of $15 \mu \mathrm{l}$ were injected into the column, where citalopram and the internal standard were separated from endogenous substances and their peak areas recorded.

\section{HLPC analysis}

All plasma samples were analysed for citalopram concentration according to a sensitive, selective, and accurate high-performance liquid chromatography (HLPC) method, which was developed and validated before the study at laboratories of I.Q.A.

The chromatographic separations and quantitative determination were performed using a high-performance liquid chromatograph from Agilent Technologies (HPST,
Prague, Czech Republic): Model 1100 series, equipped with a degassing unit, quaternary pump, autoinjector, fluorescence detector, and controlled by Agilent Chem. Station software. Chromatographic separation was performed using Symmetry ${ }^{\circledR} \mathrm{C}_{18}$ (dimethyl octadecylsilyl bonded amorphous silica; $150 \times 3.9 \mathrm{~mm}$ id.; $5 \mu \mathrm{m}$ particle size) HPLC column (Watters Corporation, Massachusetts, USA). The mobile phase consisted of acetonitrile (78:28) and ammonium formate (45 mmol/1, $\mathrm{pH} \mathrm{4.0).}$ The mobile phase was eluted at a flow rate of $0.8 \mathrm{ml} / \mathrm{min}$ at ambient room temperature. Fluorescence detection of citalopram and the internal standard was performed at an excitation wavelength of $249 \mathrm{~nm}$ and emission wavelength $302 \mathrm{~mm}$. The peak area was measured, and the peak area ratio of the drug to the internal standard and the concentration were calculated. Each analysis required a maximum of $19 \mathrm{~min}$. All samples from each single volunteer were measured on the same day in order to avoid inter-assay variation.

The calibration curves were linear over the range of $5-400 \mathrm{ng} / \mathrm{ml}$ using $1.0 \mathrm{ml}$ plasma samples. The precision of the method, expressed as coefficients of variation (CV\%), was 3.30, 9.50 and $3.15 \%$, respectively, for samples containing 20, 100 and $200 \mathrm{ng} / \mathrm{ml}$, respectively. The accuracy value was within the allowed limits.

\section{Pharmacokinetic and statistical analysis}

Pharmacokinetic analysis was performed by means of a model-independent method using the GraphPad Prism (rev. 2.01), Lotus Approach and Lotus 1-2-3 (rev. 9) computer programs. The maximum citalopram plasma concentration $\left(\mathrm{C}_{\max }\right)$ and the corresponding time of peak plasma concentration $\left(\mathrm{T}_{\max }\right)$ were taken directly from the individual plasma data. The elimination rate constant $\left(\mathrm{K}_{\mathrm{el}}\right)$ was estimated from the slope of the semilogarithmic plot of the terminal phase of the plasma concentrationtime curve calculated by linear regression and the elimination half-life $\left(T_{1 / 2}\right)$ was generated by dividing $\ln _{2}$ by the elimination rate constant $\mathrm{K}_{\mathrm{el}}$ The area under the plasma concentration-time curve $\mathrm{AUC}_{0-24}$ and the area to the infinity $\mathrm{AUC}_{0-\alpha}$ were calculated by using the linear trapezoidal method. Extrapolation of these areas to infinity $\left(\mathrm{AUC}_{0-\alpha}\right)$ was done by adding the value $\mathrm{C}_{\text {last }} / \mathrm{K}_{\mathrm{el}}$ to the calculated $\mathrm{AUC}_{0-24}$ (where $\mathrm{C}_{\text {last }}=$ the last detectable concentration). The clearance (CL) was calculated using the following equation: (dose/body wt)/AUC ${ }_{0-\alpha}$.

For the purpose of bioequivalence analysis, two-way analysis of variance (ANOVA, GLM procedure) was used to assess the effect of formulations, periods, sequences, and subjects on $\mathrm{AUC}_{0-24}, \mathrm{AUC}_{0-\alpha}$ and $\mathrm{C}_{\max }$ The difference of two related parameters was considered statistically significant for $\mathrm{p}$-values equal or less than 0.05 .

\section{RESULTS}

Both citalopram formulations (Citol and Cipramil $40 \mathrm{mg}$ tablets) were well tolerated by all the subjects; unexpected incidents that could have influenced the outcome of the study did not occur. There were no drop-outs 
Table 1. Pharmacokinetic parameters for test and reference citalopram formulations obtained from 26 healthy volunteers after oral administration of $40 \mathrm{mg}$ citalopram.

\begin{tabular}{|l|c|c|c|c|c|c|c|}
\hline \multicolumn{2}{|c|}{ Test formulation (Citol tablets) } \\
\hline Geom. Mean & $\begin{array}{c}\mathrm{AUC}_{0-24} \\
(\mathrm{ng} . \mathrm{hr} / \mathrm{ml})\end{array}$ & $\begin{array}{c}\mathrm{AUC}_{0-\alpha} \\
(\mathrm{ng} . \mathrm{hr} / \mathrm{ml})\end{array}$ & $\begin{array}{c}\mathrm{C}_{\max } \\
(\mathrm{ng} / \mathrm{ml})\end{array}$ & $\begin{array}{c}\mathrm{T}_{\max } \\
(\mathrm{hr})\end{array}$ & $\begin{array}{c}\mathrm{K}_{\mathrm{el}} \\
(1 / \mathrm{hr})\end{array}$ & $\begin{array}{c}\mathrm{T}_{1 / 2} \\
(\mathrm{hr})\end{array}$ & $\begin{array}{c}\mathrm{CL} \\
(1 / \mathrm{kg} / \mathrm{hr})\end{array}$ \\
\hline Median & 617.3 & 1183.9 & 48.5 & 2.0 & 0.0361 & 19.2 & 0.453 \\
\hline Mean & 663.6 & 1243.0 & 49.2 & 2.0 & 0.0354 & 19.6 & 0.435 \\
\hline SD & 1649.5 & 1246.4 & 50.3 & 2.1 & 0.0370 & 19.6 & 0.474 \\
\hline Min. & 164.2 & 359.7 & 13.6 & 0.6 & 0.0081 & 4.2 & 0.161 \\
\hline Max. & 928.1 & 1875.8 & 86.1 & 4.0 & 0.0057 & 30.6 & 0.997 \\
\hline
\end{tabular}

\begin{tabular}{|c|c|c|c|c|c|c|c|}
\hline \multicolumn{8}{|c|}{ Reference formulation (Cipramil ${ }^{\circledR}$ tablets) } \\
\hline & $\begin{array}{c}\mathrm{AUC}_{0-24} \\
\text { (ng.hr/ml) }\end{array}$ & $\begin{array}{c}\mathrm{AUC}_{0-\alpha} \\
\text { (ng.hr/ml) }\end{array}$ & $\begin{array}{c}\mathrm{C}_{\max } \\
(\mathrm{ng} / \mathrm{ml})\end{array}$ & $\begin{array}{l}\mathrm{T}_{\max } \\
(\mathrm{hr})\end{array}$ & $\begin{array}{c}\mathrm{K}_{\mathrm{el}} \\
(1 / \mathrm{hr})\end{array}$ & $\begin{array}{l}\mathrm{T}_{1 / 2} \\
(\mathrm{hr})\end{array}$ & $\begin{array}{c}\mathrm{CL} \\
(\mathrm{l} / \mathrm{kg} / \mathrm{hr})\end{array}$ \\
\hline Geom. Mean & 559.7 & 1176.8 & 46.2 & 2.2 & 0.0366 & 19.0 & 0.457 \\
\hline Median & 630.1 & 1167.5 & 48.6 & 2.0 & 0.0355 & 19.5 & 0.465 \\
\hline Mean & 640.6 & 1230.7 & 48.6 & 2.4 & 0.0410 & 20.2 & 0.471 \\
\hline SD & 164.0 & 381.8 & 13.5 & 1.1 & 0.0297 & 6.4 & 0.109 \\
\hline Min. & 72.1 & 679.2 & 11.8 & 1.5 & 0.0175 & 3.8 & 0.238 \\
\hline Max. & 943.1 & 2365.0 & 78.0 & 6.0 & 0.1836 & 39.7 & 0.693 \\
\hline
\end{tabular}

Table 2. Statistical evaluation (parametric analysis, logarithmically transformed data) for comparison of $\mathrm{AUC}_{0-24}, \mathrm{AUC}_{0-\alpha,}$ and $\mathrm{C}_{\max }$ of citalopram test $(\mathrm{T})$ and reference $(\mathrm{R})$ formulations.

\begin{tabular}{|c|c|c|}
\hline \multirow{2}{*}{ Citol/Cipramil ${ }^{\circledR} 40 \mathrm{mg}$} & \multicolumn{2}{|c|}{ Statistical analysis } \\
\cline { 2 - 3 } & Geometric mean (\%) & $90 \% \mathrm{CI}$ \\
\hline $\mathrm{AUC}_{0-24} \%$ ratio & 100.45 & $94.88-111.68$ \\
\hline $\mathrm{AUC}_{0--} \%$ ratio & 100.08 & $93.37-108.40$ \\
\hline $\mathrm{C}_{\max } \%$ ratio & 101.29 & $97.63-113.08$ \\
\hline
\end{tabular}

T: Test formulation (Citol tablets); R: reference formulation (Cipramil ${ }^{\circledR}$ tablets) $^{2}$

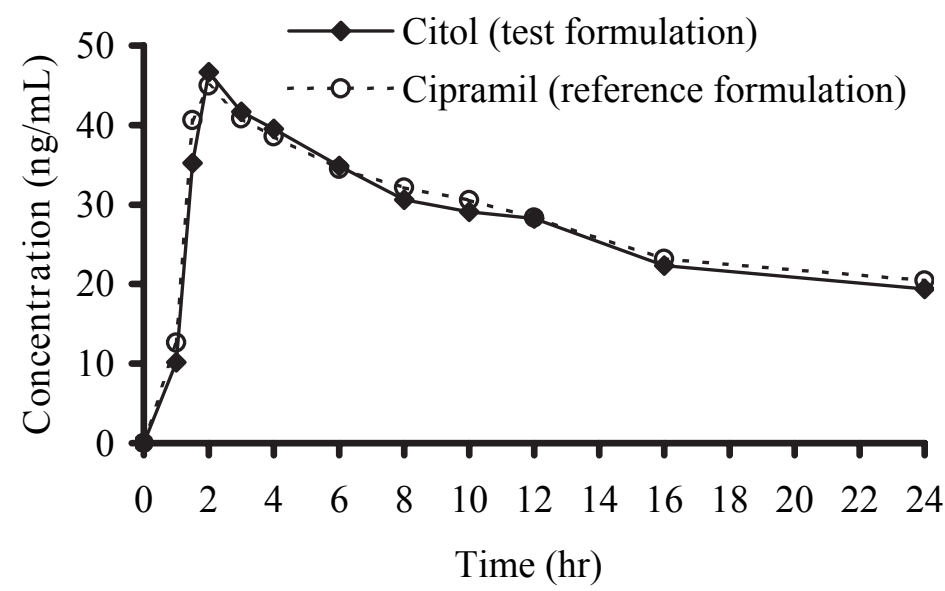

Fig. 1. Citalopram plasma mean concentrations versus time profile obtained after a single oral administration of $40 \mathrm{mg}$ of citalopram tablet formulation. 
and the volunteers who had started the study continued to the end and were discharged from the hospital in good health condition.

Both medications were readily absorbed from the gastrointestinal tract and citalopram was already measurable at the first sampling time $(1 \mathrm{~h})$ in all the volunteers. Plot of the citalopram mean plasma concentrations versus time for the two formulations over the 24-hr truncated sampling period is shown in Figure 1. Descriptive statistics of the pharmacokinetic parameters $\mathrm{AUC}_{0-24}, \mathrm{AUC}_{0-\alpha}$, $\mathrm{C}_{\max }, \mathrm{T}_{\max }, \mathrm{K}_{\mathrm{el}}, \mathrm{T}_{1 / 2}$, and $\mathrm{CL}$ for the test and reference formulations are summarized in Table 1 . The mean values of $\mathrm{AUC}_{0-24} 649.5$ (range 483.9-815.1); $\mathrm{AUC}_{0-\alpha} 1246.4$ (range 886.7-1606.1); $\mathrm{C}_{\max } 50.3 \mathrm{ng} / \mathrm{ml}$ (range 36.7-63.9); $\mathrm{T}_{\max }$ 2.1 (range $1.5-2.7$ ); $\mathrm{K}_{\mathrm{e}} 0.0370$ (range 0.0289-0.0451); $\mathrm{T}_{1 / 2} 19.6$ (range 15.4-23.8) and CL 0.474 (range 0.3130.635 ) for the test formulation and $\mathrm{AUC}_{0-24} 640.6$ (range 476.6-804.6); $\mathrm{AUC}_{0-\alpha} 1230.7$ (range 858.9-1612.5); $\mathrm{C}_{\text {max }}$ $48.6 \mathrm{ng} / \mathrm{ml}$ (range 35.1-62.1); $\mathrm{T}_{\max } 2.4$ (range 1.3-3.5); $\mathrm{K}_{\mathrm{el}}$ 0.0410 (range 0.0113-0.0707); $\mathrm{T}_{1 / 2}^{\max } 20.2$ (range 13.8-26.6) and CL 0.471 (range 0.362-0.580) for the reference formulation were determined. Based on the results from the nonparametric Wilcoxon test and the paired t-test, there were no significant differences $(\mathrm{p}>0.05)$ in $\mathrm{T}_{\max }, \mathrm{K}_{\mathrm{el},} \mathrm{T}_{1 / 2}$, and CL values for both formulations.

Table 2 shows the results of the bioequivalence analysis of the main pharmacokinetic parameters $\left(\mathrm{AUC}_{0-24}\right.$, $\mathrm{AUC}_{0-\alpha}$ and $\left.\mathrm{C}_{\max }\right)$. After log-transformation of the data, ANOVA for these parameters showed no significant difference between the two formulations ( $p>0.05)$. Relative bioavailability was found to be $100.45 \%, 100.08 \%$ and $101.29 \%$ of $\mathrm{AUC}_{0-24}, \mathrm{AUC}_{0-\alpha}$ and $\mathrm{C}_{\max }$, respectively, and the parametric $90 \%$ confidence intervals for those pharmacokinetic parameter values lie entirely within the bioequivalence acceptance limits of $80 \%-125 \%$.

\section{DISCUSSION}

The main objective of bioequivalence studies is to assure the safety and efficacy of generic formulations. Two formulations of the same drug are considered to be bioequivalent and per se therapeutically equivalent if they exhibit a comparable extent and rate of absorption, when they are administered in the same molar dose and under similar experimental conditions ${ }^{6}$. The 24-hr truncated sampling period used in this study, which is in agreement with EU guidance ${ }^{7}$ for drugs with a long half-life (e.i. citalopram $36 \mathrm{hr}$ ), demonstrated that neither AUC nor $\mathrm{C}_{\max }$ were affected for such design. Those values were statistically analysed for determination of bioequivalence or biononequivalence. Other pharmacokinetic parameters (i.e. $\mathrm{T}_{\max }, \mathrm{CL}, \mathrm{T}_{1 / 2}$ and $\mathrm{K}_{\mathrm{el}}$ ) results were used as supportive results in that truncated pharmacokinetic design.

This study was conducted on healthy volunteers according to the study protocol. All subjects received the same dosages of medication, i.e one single dose of $40 \mathrm{mg}$ citalopram in the form of the test product or one single dose of $40 \mathrm{mg}$ citalopram in the form of the reference product with a 14-day washout period. No adverse events necessitating subject withdrawal from the study were reported.

Statistical comparison of the main pharmacokinetic paramenters, $\mathrm{AUC}_{0-24}, \mathrm{AUC}_{0-\alpha}$ and $\mathrm{C}_{\max }$ clearly indicated no significant difference between Citol and Cipramil ${ }^{\circledR}$ $40 \mathrm{mg}$ tablets, in any of the calculated pharmacokinetic parameters. The obtained values were in good agreement with reported studies ${ }^{8-10}$. Since the $90 \% \mathrm{CI}$ for $\mathrm{AUC}_{0-24}$, $\mathrm{AUC}_{0-\alpha}$ and $\mathrm{C}_{\max }$ mean ratios are within the $80 \%-125 \%$ interval, it was concluded that the tested formulation $\mathrm{Ci}$ tol (40 mg tablets) elaborated by Abdi Ibrahim İlaç San. ve Tic A.Ş., Istanbul, Turkey is bioequivalent to Cipramil ${ }^{\circledR}$ $40 \mathrm{mg}$, for both extent and rate of absorption.

\section{ACKNOWLEDGMENTS}

This work was made possible by the special efforts of M. Vedat Egilmez, Business Development Director of Abdi Ibrahim İlaç San. ve Tic A.Ş., Istanbul, Turkey. We thank the University Hospital in Olomouc medical and paramedical staff for their valuable contribution. M.H. is supported by Ministry of Education, Youth and Sport Research Grant No.: 6198959216.

\section{REFERENCES}

1. Hyttel J. (1982) Citalopram-pharmacological profile of a specific serotonin inhibitor with antidepressant activity. Prog Neuopsychopharmacol Biol Psych 6, 277-95.

2. Milne RJ, Goa KL. (1991) Citalopram. A review of its pharmacodynamic and pharmacokinetic properties, and therapeutic potential in depressive illness. Drugs 41, 450-77.

3. Mendels J, Kiev A, Fabre LF. (1999) Double-blind comparison of citalopram and placebo in depressed outpatients with melancholia. Depression and Anxiety 9, 54-60.

4. Montgomery SA. (1995) Selecting the optimum Therapeutic dose of serotonin reuptake inhibitors: Studies with citalopram. Int J Clin Psychopharm 10 (suppl. 1), 23-27.

5. FDA guidance. Guidance for industry: Statistical approaches to establishing bioequivalence, Rockville, MD, 31 January 2001.

6. Chow SC, Liu JP. Design and analysis of bioavailability and bioequivalence studes; Marcel Dekker: New York, 1992.

7. EMEA guidance. Note for guidance on the investigation of bioavailability and bioequivalence (CPMP/EWP/QWP/1401/98). London, 26 July 2001.

8. Oyehaug E, Ostensen ET, Salvasen B. (1982) Determination of the antidepressant agent citalopram and metabolites in plasma by liquid chromatography with fluorescence detection. J Chromatogr 227, 129-35.

9. Dalgaard L, Larsen C. (1999) Metabolism and excretion of citalopram in man: Identification of o-acyl- and n-glucuronides. Xenobiotica 10, 1033-41.

10. Gutierrez MM, Abramowitz W. (2000) Pharmacokinetic comparison of oral solution and tablet formulations of citalopram: A singledose, randomised, cross-over study. Clin Ther 22, 1525-32. 